\title{
LA OPINIÓN PÚBLICA EN LA SOCIEDAD DE LA INFORMACIÓN: UN FENÓMENO SOCIAL EN PERMANENTE CAMBIO
}

\author{
Juan Antonio García Galindo \\ Universidad de Málaga
}

RESUMEN: El nuevo escenario de la comunicación surgido a finales del siglo XX está transformando en el siglo XXI las relaciones entre los emisores y productores de la información y los receptores o destinatarios de la misma. Las posibilidades abiertas por las nuevas tecnologías de la información y de la comunicación permiten la interacción entre unos y otros, convirtiendo a los ciudadanos, hasta ahora receptores tradicionales de la comunicación, en emisores y productores de contenidos. Esta ruptura en la linealidad de los procesos comunicativos ha dado lugar a la multiplicación de flujos de información en diferentes direcciones, revalorizando el papel del individuo como productor y usuario de la comunicación, y replanteando incluso el concepto vigente de opinión pública, fenómeno social que también asiste hoy a su transformación. Estas nuevas fronteras de la comunicación que parecen situarnos ante la mayor democratización de la comunicación social en toda su historia, nos sitúan, sin embargo, ante un panorama lleno de incertidumbres que exigen su reflexión y estudio.

Palabras clave: Sociedad de la Información, opinión pública, información, periodismo, comunicación, nuevas tecnologías.

ABSTRACT: The new scene within communication that commenced towards the end of the 20th century has transformed, in the 21st century, the relationships between broadcasters, those producing the information, and recipients. The possibilities that have arisen thanks to advancement in news and information allow for interaction between both. This development has made citizens not only communication recipients, in the traditional sense, but also broadcasters and producers of content. The breakdown in the linear process of communication 
has caused the multiplication of information outlets in different directions, reevaluating the role of the individual as producer and user of communication. This multiplication has also reassessed the concept of public opinion. These new boundaries in the world of communication seem to place us face to face with the greatest democratization of social communication in world history. However, it also presents us with a panorama of uncertainty which demands reflection and further study

Keywords: Information Society, public opinion, information, journalism, communication, new technology.

\section{Introducción: hacia una nueva opinión pública}

El presente objeto de estudio empieza a ocupar numerosas páginas en la literatura científica sobre periodismo y comunicación, habida cuenta de la relación tan estrecha que estas actividades sociales mantienen con el concepto de opinión pública. Este aumento del interés viene determinado, entre otras cosas, por la crisis de credibilidad por la que atraviesa en estos momentos el periodismo, y por los cambios que las nuevas tecnologías han producido en los usos y consumos de la comunicación. Es objetivo de estas líneas contribuir a ese debate incipiente acerca de la forma en que se configura la opinión pública en esta época de profundos cambios sociales y económicos, que la crisis económica no hace sino aumentar. Hacer esta reflexión en el marco de la nueva sociedad mediática y tecnológica conlleva sus riesgos, pues los cambios que se están produciendo son tan acelerados que sus consecuencias pueden percibirse de manera errónea.

El mundo que nos rodea es un mundo de comunicación. Un mundo actualmente globalizado gracias a las tecnologías de la comunicación que han hecho desaparecer las barreras que antes imponía la geografía y el tiempo (el tiempo que transcurría entre la producción del acontecimiento y la elaboración y difusión de la información por parte de los medios de comunicación). Hoy las noticias circulan de manera prácticamente instantánea desde cualquier parte del mundo. Pero lo que ahora nos parece normal, antes no lo era. Los medios de comunicación han sido y son los vehículos de la información, los que permiten que conozcamos lo que pasa a nuestro alrededor, pero también lejos de nosotros. La prensa, la radio y la televisión han sido durante muchos años los únicos medios de comunicación a través de los cuales conocíamos el mundo, pero hoy este monopolio es compartido en el nuevo escenario digital con otros medios y tecnologías móviles.

1. Víd. AGUADO, Juan Miguel, y JOSÉ MARTíNEZ, Inmaculada (Coords.) (2008): Sociedad móvil. Tecnología, identidad y cultura. Madrid, Biblioteca Nueva. 
El gran desarrollo que han experimentado las nuevas tecnologías aplicadas a la comunicación social e interindividual desde los años ochenta del pasado siglo ha permitido que nos situemos ante un horizonte sin fronteras que está transformando las relaciones humanas en el seno de la sociedad actual. Pero lo verdaderamente trascendente de esta revolución tecnológica es que se haya roto el predominio de la unidireccionalidad de la comunicación (es decir, de aquella cuyos flujos van en una sola dirección, desde los emisores a los destinatarios), y que haya abierto la posibilidad de la interactividad o interacción entre los emisores y los ciudadanos, y entre estos entre sí ${ }^{2}$. Esto es justamente lo más importante, a mi entender, y lo que abre nuevas expectativas a la construcción de la opinión pública contemporánea.

\section{El concepto de opinión pública en la Sociedad de la Información}

Si hasta finales del siglo pasado, la opinión pública, es decir, lo que opina la sociedad, se formaba fundamentalmente a partir de la opinión publicada, es decir, de aquella que se encontraba en los medios de comunicación impresos o audiovisuales, en la actualidad esto está cambiando sustancialmente. La opinión pública actual no se construye solo a partir de lo que dicen los medios, sino a través de la interacción con los medios y, lo que es más importante, y a evaluar en el futuro, se construye al margen de los propios medios.

Sin duda, los medios de comunicación y, en los últimos años, Internet, siguen siendo el gran espacio público de la sociedad, el ágora en el que se presentan y se discuten los temas más destacados, aquellos que los medios han convertido previamente en su agenda. La opinión pública actúa como reflejo de los propios medios y se convierte en la imagen que ellos proyectan. Desde esta perspectiva, los ciudadanos son meros receptores pasivos que aceptan como suyas las opiniones e interpretaciones de la agenda mediática ${ }^{3}$. No obstante, en

2. Las tecnologías de la información y de la comunicación (TIC) son tecnologías de mediación que implican el intercambio de comunicación entre dos o más individuos. Ésa es su naturaleza, que otorga a los usuarios un grado de libertad inexistente en su relación con los medios tradicionales. Mediante estas tecnologías las diferencias entre emisor y receptor desaparecen para situarse ambos en el mismo plano del proceso de la comunicación. A este respecto escriben Cola, Prario y Richeri, "Oggi invece con le TIC ci si riferisce specialmente a Internet a al telefono cellulare, ossia a tutte quelle tecnologie che implicano uno scambio di comunicazione (...). Le TIC dovrebbero essere considerate come tecnologie di mediazione dove la comunicazione viene intesa come contingenza economica, politica, sociale e materiale. Pertanto la comunicazione mediata dalle TIC non può prescindere dall'interattività, dalle reti sociali che vengono a crearsi e dal suo carattere pervasivo". COLA, Marta, PRARIO, Benedetta, y RICHERI, Giuseppe (2010): Media, tecnologie e vita cuotidiana: la domestication. Roma, Carocci editore, pág. 103.

3. "Al final, lo que llamamos opinión pública no es sino la imagen pública que proyectan los medios de comunicación sobre algunos temas relacionados con el bien público y que el 
los últimos años se aprecia una cierta ruptura en esa hegemonía de los medios de comunicación convencionales en la conformación de la opinión pública, que es aún difícil de detallar porque coexisten viejas y nuevas formas de intervención comunicativa en el espacio público que pueden llegar a contrarrestarse: los emisores tradicionales, o sea, los medios de comunicación impresos y audiovisuales; y los nuevos emisores, que son los propios ciudadanos que a través de las tecnologías más actuales comienzan a intervenir en dicho espacio. Esta dialéctica entre los dos tipos de emisores no se ha resuelto, pese a sus diferentes intereses y objetivos, en una situación de síntesis superadora porque pueden llegar a ser complementarios, pero se produce en un panorama muy dinámico que no es ajeno al mantenimiento del control de los grandes flujos de información por parte de los grandes conglomerados mediáticos.

Por otra parte, esta irrupción de los ciudadanos en la esfera comunicativa es aún muy reciente, aunque viene a romper el monopolio de los medios de comunicación en la construcción de la opinión pública y de la cultura misma. A saber, la opinión pública en su acepción más clásica debe producir una conciencia grupal sobre la existencia de una base cultural común. En el nuevo estado de cosas, estos aspectos empiezan a verse modificados paulatinamente, surgiendo una conciencia más diluida sobre una base cultural resultante de una amplia segmentación de las audiencias y de una estructura social multicultural.

Hoy día, los ciudadanos dotados de la tecnología adecuada (medios móviles y ordenadores personales de última generación, etc.) pueden interactuar de hecho con sus familiares, amigos, o con la administración electrónica, resolviendo muchas de las gestiones que antes se hacían solo personalmente, y estableciendo una comunicación de doble sentido, que no pasa necesariamente por filtros sociales, políticos, culturales o incluso periodísticos. Y que además se puede ampliar en forma de red que se despliega a través de la sociedad. Este es el caso de las redes sociales.

Estas extraordinarias posibilidades que encierran las actuales tecnologías de la comunicación cumplen una función social indudable, ya que generan nuevos espacios de socialización virtual que no tienen por qué sustituir el encuentro físico y personal, y abren nuevas y diferentes vías al ocio y al entretenimiento, restando tiempo al consumo televisivo que aún hoy ocupa el primer puesto en el ranking de los usos del tiempo de los jóvenes españoles $^{4}$. Esta comunicación mediada por las nuevas tecnologías ha multiplicado

ciudadano acepta como propios, bajo la impresión de que es elaboración propia (racionalidad), cuando en realidad no es sino la confirmación del poder (efectos) que los medios ejercen sobre la población". MONZÓN, Cándido (2001): "Opinión e imagen pública. Una sociedad bajo control", en: Palabra Clave, 9, pág. 21.

4. Según datos de la segunda oleada del Estudio de General de Medios de 2011, el porcentaje de penetración de la televisión en la dieta mediática de los españoles ha sido del 88,4\%. 
los intercambios de contenido en el seno de la sociedad, sirviendo a su vez de altavoz de numerosas corrientes de opinión, que antes eran inimaginables. Si a ello unimos la importancia de Internet, como medio de medios, o como gran enciclopedia virtual puesta a disposición de los usuarios de todo el mundo, podemos darnos cuenta de que las fuentes del conocimiento se han ido desplazando desde los archivos y bibliotecas tradicionales a este nuevo soporte que parece carecer de límites. Este hecho ha permitido igualmente que los ciudadanos, sin diferenciación alguna, puedan acceder a contenidos antes reservados a unos pocos.

Todas estas transformaciones han acabado por afectar a las instituciones dedicadas a la transferencia de la información y del conocimiento, entre ellas a la escuela y a la universidad, así como a los medios de comunicación. Estas instituciones no tienen más remedio que ir adaptándose a este nuevo escenario tecnológico y cultural, puesto que la cultura es, entre otras cosas, resultado de la interacción del individuo con el medio a través de la tecnología. Los mismos procesos de enseñanza-aprendizaje han de ser adaptados a unos estudiantes que fuera del entorno escolar aprenden otros contenidos (o refuerzan los de la escuela) de manera autónoma. La escuela y los medios de comunicación deben reubicarse en este nuevos escenario, pero al mismo tiempo deben repensar sus propias tareas y funciones ante unos destinatarios de sus mensajes que cuando llegan a la escuela o cuando ven la televisión ya tienen una imagen previa y unos prejuicios determinados de muchos de los contenidos que se trasmiten desde ellos. Si a finales del siglo XX ya la mayor parte de los contenidos que utilizaban los jóvenes en sus espacios de sociabilidad procedían de los medios de comunicación, con toda probabilidad en la actualidad la irrupción y generalización social de las nuevas tecnologías ha aumentado estas cifras, y ha favorecido el desarrollo de un conocimiento autónomo y/o compartido, que no ha pasado necesariamente a través de los filtros de la institución educativa. Esto plantea nuevos retos y desafíos a los medios de comunicación tradicionales, pero también a la escuela, que ha de incorporar un currículum abierto que la sitúe de nuevo en el centro del sistema educativo y de respuesta a las nuevas demandas sociales.

Esta nueva sociedad tecnológica que ofrece numerosas posibilidades para la intercomunicación, también plantea un reto a los ciudadanos. Y ése es la necesidad de estar formados e informados (de estar en definitiva en un permanente proceso de aprendizaje) para poder opinar adecuadamente, libremente, y para saber desenvolverse bien en ese bosque del conocimiento que están creando las nuevas tecnologías de la comunicación y de la información. Porque una sociedad formada, una sociedad educada, es en definitiva la base de lo que se ha dado en Ilamar Sociedad del Conocimiento. La cultura y la educación son un valor añadido para cada uno de los ciudadanos, pero lo es también para la sociedad en su conjunto que se verá en ese caso beneficiada por ello. 


\section{Una opinión pública global}

Una sociedad globalizada tiende a crear una opinión pública igualmente globalizada, pero no siempre es así. Los grandes conglomerados mediáticos, que controlan los grandes flujos de comunicación internacional a través de las grandes agencias de información, siguen ejerciendo una enorme influencia sobre la mentalidad social, sirviendo de paraguas ideológico y conceptual de una opinión pública cada vez más globalizada, al menos en torno a aquellos grandes temas que no desean ver cuestionados. Pero también bajo ese paraguas sobreviven diferentes niveles y grados en esa opinión publica transnacional producto de la globalización informativa. De hecho, en muchas ocasiones se producen resistencias nacionales frente a la uniformidad de la información global, dando lugar, con el objetivo de no quedar absorbidos por ella, a una determinada protección informativa, sobre todo cuando los hechos o acontecimientos afectan a la credibilidad de una nación o Estado. Estas particularidades son una muestra de las excepciones existentes a la regla universal de la información globalizada.

Otra excepción a dicha regla es la que se produce en el seno de la sociedad cuando los ciudadanos no siguen las pautas y las reglas de la globalización informativa y cultural. Siendo cierto que el monopolio hegemónico de los grandes medios tiende a invadir culturas informativas diferentes, siguiendo la misma lógica de la teoría de la dependencia, no lo es menos el hecho de que a nivel de los ciudadanos se están produciendo reacciones en cadena ante una uniformidad que resulta totalmente ajena a sus problemas cotidianos. Esta reacción tiene su raíz en la crisis económica y en el descontento ciudadano ante sus políticos y ante las respuestas que estos están dando a sus problemas; así como en las nuevas tecnologías de la comunicación que ofrecen un uso cada vez más individualizado, liberando al individuo de los corsés que le imponen los mensajes de los medios convencionales, unidireccionales y sin posibilidad de respuesta. Las respuestas de los indignados del $15 \mathrm{M}$ en España, pero también las de las revueltas árabes, como las que están ocurriendo en otras partes del mundo, están en la base de estos nuevos fenómenos sociales que alteran el comportamiento tradicional de la opinión pública en las sociedades contemporáneas, con independencia de su nivel de desarrollo. La penetración de las tecnologías móviles en el mundo no está siempre asociada al nivel económico general de una población, pues aunque el acceso a las mismas se ha producido, sobre todo, entre aquellos sectores de la sociedad con mayor nivel de instrucción o de renta, el resto de la población también ha podido acceder a ellas. Afirma James E. Katz que "incluso en algunos de los países más pobres el acceso a la tecnología móvil presenta índices notables" ${ }^{\prime \prime}$. Son, pues, estos sectores, dotados

5. KATZ, James E. (2008): "Cuestiones teóricas en torno a medios móviles y comunicación", en: AGUADO, Juan Miguel, y JOSÉ MARTíNEZ, Inmaculada (Coords.) (2008): Sociedad móvil. Tecnología, identidad y cultura. Madrid, Biblioteca Nueva, pág. 28. 
de esas tecnologías, los que han canalizado a través de ellas sus reivindicaciones e inquietudes en los países de menor desarrollo. ¿Significa esto que hay que hablar de un nuevo sentido de la opinión pública? Probablemente sí, pero como venimos señalando es preciso ser cautos para no perder la perspectiva del análisis. El problema es realmente complejo, e intervienen en él numerosos factores, entre los cuales hemos de tener en cuenta el grado de formación de los ciudadanos, y por tanto de educación, o su facilidad de acceso a las nuevas tecnologías, e incluso otros factores externos que cohesionan una respuesta colectiva.

Hay otro elemento a tener en consideración, los movimientos sociales que se están produciendo en la actualidad son resultado, entre otros factores, del papel que desempeñan las tecnologías de la información y de la comunicación en la difusión rápida e inmediata de los mensajes y de las convocatorias. La opinión pública del pasado siglo XX, sobre todo del periodo posterior a la Segunda Gran Guerra, acabó siendo una opinión pública pasiva, exclusivamente receptora e incubadora de los mensajes de los medios (paradójicamente, de unos medios que defendían la consolidación del estado liberal-democrático y de la sociedad del bienestar), mientras que en la actualidad el clima de opinión pública que se ha ido creando en los países ribereños del mediterráneo, por poner un ejemplo, incluyendo a nuestro país, tienen también el objetivo de pasar a la acción. La crisis les ha empujado, sin duda, a ello. Este hecho es digno de ser tenido en cuenta, porque modifica sustancialmente el concepto de opinión pública que ha sido dominante, aquel que asume como suyos las ideas e interpretaciones de los medios de comunicación sin recurrir a más movilización que la del voto consciente o no cada cuatro años.

En el caso español, que tiene obviamente sus particularidades propias, el planteamiento resulta igualmente complejo, pues se trata de un clima de opinión creado a través de numerosas fuentes complementarias y alternativas, a las que se une la movilización popular de sectores de la población antes ajenos a cualquier tipo de reivindicación o lucha social y que ahora se incorporan junto a los jóvenes en una protesta generalizada como reacción a unos partidos y a un sistema político que parecen no responder a sus demandas. Qué duda cabe que se trata de movimientos que tienen una base común, quizás la desesperanza ante la situación, y que se movilizan de manera cohesionada y organizada para mostrar su disconformidad frente a los sectores dominantes de la población que controlan los resortes de la política o de la economía (políticos, grandes empresarios, jueces, etc. ${ }^{6}$. Distingue a estos movimientos un buen nivel de

6. Según el Barómetro del Centro de Investigaciones Sociológicas, de mayo de 2011, los tres principales problemas de España en la actualidad son: el paro (84,1\% de los encuestados); la economía (46,5\%), y la clase política y los partidos políticos (22,1\%). Como puede entenderse fácilmente, los dos primeros tienen una relación directa entre sí, y el tercero también porque se perciben como responsables de la situación que da lugar a aquellos. 
autoorganización, y unos objetivos de exigencia democrática, pese a que este tipo de movimientos pueden ser utilizados por individuos y colectivos antisistema.

Así pues, la tradicional relación entre opinión pública y opinión publicada puede haber comenzado a desaparecer en el nuevo escenario tecnológico y comunicativo, al ampliarse de tal manera los canales de comunicación que el acceso de los ciudadanos a la información y a la opinión se ha multiplicado y fragmentado, provocando un panorama heterogéneo, de distinta intensidad y valor referencial. Son los medios de calidad los que en este panorama continúan todavía como conductores de una opinión pública cada vez más formada y con acceso a fuentes alternativas de información, pero que se encuentra desorientada y que demanda un cambio en esos medios.

\section{Opinión pública sin periodismo}

El periodismo y los medios de comunicación han sido desde el siglo XVIII los instrumentos más importantes de la opinión pública, de la imagen colectiva que la sociedad tenía de las cuestiones sociales. Las últimas teorías de la comunicación han puesto el énfasis en este aspecto. Filósofos, politólogos, sociólogos o comunicólogos (Noelle-Neumann, Luhmann, Mc Leod, McCombs, etc.) han coincidido en esta idea y en el rol desempeñado por los medios de comunicación, aunque hayan diferido en la determinación del factor o factores principales de la opinión pública.

La crisis que atraviesa en la actualidad el periodismo no es solo una crisis empresarial o económica, producto de la crisis general, sino que lo es de identidad del propio periodismo, de su credibilidad y de su razón de ser. El periodismo ha dejado de ser una profesión valorada en nuestro país, en el que llegó a ser una de las de mayor prestigio. Durante la transición política, los periodistas y los medios de comunicación desempeñaron un papel muy importante en el proceso de cambio. Políticos y periodistas tuvieron, por la misma razón, un gran reconocimiento social. Paradójicamente, décadas más tarde, con la democracia consolidada en nuestro país, políticos y periodistas han perdido aquella reputación. Ni la clase política ni los periodistas actuales parecen capaces de dar una respuesta satisfactoria a las demandas de la sociedad española del siglo XXI. Pero esta pérdida de reputación es el resultado de otros factores que les afectan directamente: la corrupción de la política, la crispación entre los partidos, la devaluación de los contenidos y de los argumentos en los medios de comunicación, la ausencia de debate intelectual en la política y en el periodismo español, la precariedad laboral de los periodistas, la incapacidad de las empresas periodísticas para entender la función que realizan, la mercantilización excesiva de la información, etc. El periodista Steve Coll, en cita recogida por Felipe Sahagún, asegura que "la actual crisis en el periodismo no es tanto 
una crisis de lectores como una crisis de lectores rentables para los medios" ${ }^{\prime \prime}$. El actual modelo de negocio de las empresas periodísticas españolas antepone el mantenimiento de sus márgenes de rentabilidad empresarial a cualquier otra consideración: la preservación de los puestos de trabajo, la especialización de la oferta informativa y de los profesionales, o la calidad de los productos informativos, etc., para acabar atribuyendo exclusivamente a factores externos las causas de la crisis periodística. Si, por ejemplo, la prensa pierde número de lectores, como lo demuestran todas las cifras consultadas ${ }^{8}$, lo es, entre otras cosas, por el escaso atractivo que la prensa actual tiene para ellos, que son soberanos para decidir qué producto eligen (cuanto más formados, más exigentes), dada la existencia de nuevos canales y fuentes de información alternativos o complementarios, y los nuevos usos de consumo mediático.

Ha escrito artísticamente José Luis Dader que la "sociedad de la información podría lograrse a cambio de una sociedad sin periodismo" ${ }^{\prime \prime}$, y que el exceso de mensajes contradictorios y el ruido informativo acaban creando desorientación en el ciudadano. Curiosa paradoja. En una sociedad denominada de la información y del conocimiento, en la que los medios y formas de la comunicación social han acabado convirtiéndose en el centro de todo un engranaje políticoeconómico (o ideológico-productivo), los ciudadanos, sin embargo, no encuentran referencias de autoridad. Según Serge Halimi, citado por Dader, el panorama se reduce a "medios de comunicación cada vez más presentes, periodistas cada vez más dóciles, (y) una información cada vez más mediocre ${ }^{\prime 10}$. En este sentido, el sistema social de significación que caracteriza a esta etapa del capitalismo informativo resulta fragmentario y débil, pues se han diversificado los canales, segmentado los públicos, y se han devaluado los contenidos. Es precisamente la debilidad de la información y, por tanto, del periodismo, uno de los factores que más sorprenden en esta nueva organización socioeconómica del capitalismo que denominamos sociedad de la información, sociedad de la comunicación o sociedad del conocimiento. El periodismo débil, que no genera inteligencia, que no reduce la incertidumbre, que es volátil, que apenas proporciona claves para interpretar adecuadamente el mundo, que no valora la formación de sus profesionales ni la de sus destinatarios, que ha roto las barre-

7. SAHAGÚN, Felipe (2009): "El futuro del periodismo", en: Cuadernos de Periodistas, 17, pág. 23.

8. Según datos de la segunda oleada del Estudio General de Medios de 2011, los diarios siguen retrocediendo situándose en un $37,6 \%$ de penetración. Curiosamente, los diarios de información general pierden 226.000 lectores mientras que los diarios deportivos ganan 47.000 lectores.

9. DADER, José Luis (2009): "Periodismo en la hipermodernidad: consecuencias cívicas de una identidad débil (y algunas vías de reconstrucción)", en: Textual \& Visual Media, 2, 2009, pág. 148.

10. Ibíd., pág. 161. 
ras entre la información y la opinión, o que ha devenido en espectáculo, no solo no contribuye al reforzamiento de la opinión pública sino que la desorienta.

Los medios de comunicación siguen desempeñando en las sociedades avanzadas un rol hegemónico en la construcción social de la realidad, por encima de instituciones como la escuela o la familia ${ }^{11}$, hegemonía consolidada desde los años de desarrollo de la sociedad de masas hasta la actualidad. Sobre todo a partir de entonces se ha venido reiterando la idea, debido al poder efectivo de los medios, "de que quien controle y esté en los medios, controlará la sociedad"12. Esta afirmación se ha convertido desde entonces en una estrategia de los medios de comunicación, que ha sido rápidamente asimilada en las democracias occidentales por el poder político, que ha visto en la alianza con ellos una manera de garantizar el control de la acción política. Esta comunión de intereses económicos y políticos no es nueva en el ámbito de la comunicación, antes al contrario ha sido una constante histórica.

El problema es que ahora los fines para los que se usan los medios de comunicación por parte de ciertos sectores de la clase política nada tienen que ver con el pasado, cuando los medios de comunicación, y en particular el periodismo, ejercieron unas funciones claras de compromiso con la implantación y consolidación de la democracia. En la actualidad, estas alianzas se alejan de estos propósitos, razón por la cual podemos observar muchos déficits en nuestras democracias, puesto que el gran poder de influencia que los medios siguen teniendo no se ha puesto al servicio de ellas, profundizando y avanzando en la democracia, y adaptándola a los nuevos tiempos. La conversión de la escena política en espectáculo ${ }^{13}$, donde la imagen o la apariencia priman sobre la realidad, y la transformación de los periodistas de élite en sujetos activos de la vida política, han creado un espacio de intersección entre el periodismo y la política,

11. GÓMEZ-MOMPART, Josep Lluis (2009): "Construir la sociedad de la comunicación desde la historia", en GARCÍA GALINDO, J.A., VASALLO DE LOPES, M ${ }^{a}$ I., y VERA BALANZA, $M^{a}$ T. (Coords.), Construir la sociedad de la comunicación. Madrid, Tecnos, pág. 76.

12. MONZÓN, Cándido (2001): Op. Cit., pág. 24.

13. Algunos autores han estudiado el desplazamiento de la política desde los géneros informativos a los contenidos vinculados al entretenimiento y al espectáculo, fenómeno denominado como Política Pop, que va más allá de la popularización de la política para convertirse en un nuevo modo de acercamiento a ella, a través de un lenguaje y unos formatos diferentes a los que tradicionalmente utilizaba la política para llegar a la opinión pública. A este respecto, puede ser de interés la consulta, entre otras, de las siguientes obras: MAZZOLENI, G. i SFARDINI, A. (2009): Política Pop. Da 'Porta a porta' a 'L'isola dei famosi'. Bologna, Il Mulino; STREET, J. (1996): Politics and Popular Culture. Cambridge, Polity; del mismo autor (2001): Mass Media, politics and democracy. New York, Palgrave; MAAREK, Ph. J. (2009): Marketing político y comunicación. Claves para una buena información política. Bacelona, Paidós; y PUJADAS CAPDEVILA, Eva (2007): "Formas narrativas y nuevos pactos ficcionales. Redefinición de los límites de la comunicación audiovisual. El caso de los talk shows y los reality shows", en: Trípodos, vol. II, mayo 2007. 
así como un intercambio de roles, que impiden apreciar con claridad donde acaba uno y dónde empieza el otro ${ }^{14}$. Esta confusión en el seno del espacio público, puesto que unos y otros forman parte importante del mismo, generan desorientación e incertidumbre en la opinión pública, cuando no rechazo.

Esto es observado también por los ciudadanos, quienes reivindican precisamente la necesidad de avanzar en estas reformas democráticas, más justas y solidarias, que defiendan los intereses de la gran mayoría de la población. Cuestiones que están y han estado siempre en la base de toda acción política democrática. El desmantelamiento progresivo del estado del bienestar, la acomodación de los políticos a situaciones de privilegio, y la ambición desmedida de las grandes empresas y de los bancos forzando políticas económicas sometidas exclusivamente a criterios macroeconómicos y a directrices del capitalismo internacional, son factores que están dando lugar a una situación compleja y llena de incertidumbres.

A este respecto, Fuentes y Fernández Sebastián Ilaman la atención sobre la relación divergente entre democracia y tecnología en el siglo XXI, resultado de los fuertes cambios sociales y tecnológicos que se viven en nuestros días frente al estancamiento de la realidad política. Para estos autores, se produce la colonización del lenguaje político por el de las tecnologías de la comunicación, al mismo tiempo que la democracia carece de capacidad de respuesta ante los grandes desafíos planteados por la aceleración del tiempo histórico ${ }^{15}$.

\section{La vida social digital: redes sociales vs. movimiento sociales}

Pese a que los jóvenes siguen haciendo uso de los medios tradicionales (sobre todo de la televisión), el consumo de Internet y de las redes sociales han aumentado considerablemente porque estas tecnologías ofrecen nuevas posibilidades de expresión, información y entretenimiento, además de la de interaccionar con los amigos en el espacio virtual. A este respecto escribe Ulla Carlsson, que son los medios de conversación y entretenimiento interactivo los

14. Víd. MONZÓN, Cándido (2001): Op. Cit., págs. 23-24.

15. "No es que la democracia no evolucione, sino que la velocidad a la que lo hace es incomparablemente menor, como si la globalización comportara dos tiempos distintos: el tiempo (lento) de las transformaciones políticas y el tiempo (vertiginoso) del cambio tecnológico y social. No se trata, en todo caso, de dos dimensiones estancas, que evolucionan por separado. El siglo XXI parece apuntar, por el contrario, a una irrupción creciente de las nuevas tecnologías en las prácticas sociales y políticas y, como consecuencia de ello, a una paulatina 'colonización' del lenguaje político por el de las tecnologías de la comunicación. Esta renovación de la política 'desde fuera' no invalida, sin embargo, la sensación de que la democracia carece, por sí misma, de capacidad de respuesta ante los grandes desafíos planteados por la aceleración del tiempo histórico". FUENTES, Juan F. y FERNÁNDEZ SEBASTIÁN, Javier (2008): "El lenguaje de la democracia: ¿crisis conceptual o crisis del sistema?", en: Revista de Occidente, 322, pág. 33. 
que han experimentado un mayor crecimiento en el número de usuarios $^{16}$. El distanciamiento de los jóvenes de los medios tradicionales es una realidad, lo que pone en cuestión el papel que los medios quieren seguir desarrollando en la sociedad actual. El creciente uso de Internet como fuente de información, a la que se le da la misma o mayor credibilidad que a los medios tradicionales, es un ejemplo clave de los cambios en los hábitos de consumo de las audiencias. Asimismo, la existencia de un uso extenso y dinámico de las tecnologías móviles confirma que se están produciendo cambios notables en el espacio y el comportamiento públicos ${ }^{17}$.

Según datos del informe sobre la Sociedad de la Información en España del pasado año ${ }^{18}$, Internet alcanzó en 2010 un grado de penetración en nuestro país del 64,2 \%, lo que representó 26,9 millones de internautas, siendo los menores de 24 años el segmento de población de mayor penetración, sobrepasando el $94 \%$. Este segmento de población considera además que este servicio es fundamental en sus vidas. En este sentido, el uso de Internet es un factor de organización de la vida privada de estos jóvenes, que condiciona su tiempo de ocio y determina su relación con sus amigos. En todos los casos, el tipo de actividades mayoritarias que se realiza en la red es: compartir y comentar fotos, intercambiar mensajes privados, actualizar el perfil o informarse. En definitiva, leemos en el informe citado, "los contenidos que se comparten constituyen el 'pegamento social' que ayuda a cohesionar esa red"19. Con respecto a los medios móviles, "Gergen -citado por Katz- sostiene que los teléfonos móviles pueden restaurar la privacidad y la intimidad que fueron relegadas por las tecnologías del siglo XX, especialmente la televisión" ${ }^{\prime 20}$. Cohesión social y privacidad son, pues, dos de las grandes cualidades que caracterizan el uso de las

16. CARLSSON, Ulla (2011): "Los jóvenes en la cultura de los medios digitales", en Infoamérica, 5, pág. 103. Resulta muy interesante la descripción de esta autora sobre este fenómeno: "Internet -escribe Carlsson- ofrece campos de comunicación, información, conocimiento, compras, entretenimiento, juegos, formación de opinión, creatividad, arte y muchísimo más. La web mundial ofrece medios bien conocidos como la radio, la televisión, el cine, la música y los periódicos en diversas plataformas de la web y, en algunos casos en nuevos formatos que interactúan. Pero lo que llamamos 'medios sociales' es algo totalmente diferente que permite la combinación de tecnología, interacción social y contenido generado por el usuario. Cuentan con diferentes tipos de forums de debates: comunidades, blogs y otros tipos de comentarios. Las actividades en línea que muestran el crecimiento más acelerado entre los jóvenes son aquellas que posibilitan la interacción de individuos, por ello llamadas 'redes sociales', como Facebook y Myspace, es decir, los medios de conversación y entretenimiento interactivo".

17. KATZ, James E. (2008): Op. Cit., pág. 23.

18. La Sociedad de la Información en España. 2010. Ariel, Colección Fundación Telefónica. Consultado en: http://e-libros.fundacion.telefonica.com/sie10/.

19. Idem.

20. KATZ, James E. (2008): Op. Cit., pág. 24. 
tecnologías actuales de la información y de la comunicación, y que justifican plenamente su expansión.

Como ha puesto de relieve Montserrat Quesada, como consecuencia de los atentados del 11-M, en 2004 se produjo un cambio cualitativo en la orientación de la opinión pública española. La información de los medios estuvo en aqueIlos momentos -escribe la autora- demasiado apegada a las fuentes oficiales, lo que provocó la reacción de los ciudadanos que buscaron otro tipo de información en las Webs, y que recurrieron al envío masivo de SMS para movilizarse e informarse sobre la realidad de los acontecimientos ${ }^{21}$. Éste fue, sin duda, un claro precedente de las movilizaciones del 15-M, y de la forma de proceder de este movimiento a través de los medios móviles y de las redes sociales. Sin embargo, como apunta Katz, "la comunicación móvil puede redundar en una mayor eficacia no sólo social, sino también de control policial"222. En efecto, las tecnologías no son neutras y sus efectos dependerán en todo momento del uso que se haga de ellas. Cierto es su efecto multiplicador, y ciertas sus cualidades anteriormente mencionadas, pero su capacidad para la coordinación social o su condición de motor del cambio en la sociedad dependerá obviamente de su uso, y de las ideas que estén detrás del mismo. Todo proyecto de cambio social empieza primero por las ideas, por la observación y el análisis de la realidad, y por la adopción de las políticas adecuadas. En ese contexto las tecnologías son el vehículo y las herramientas para conseguir los objetivos trazados, aunque los resultados de la socialización de estas tecnologías de uso individual pueden resultar impredecibles. Qué duda cabe que se está produciendo una transformación cualitativa del espacio público que puede favorecer la democratización de la comunicación social, pero esta apariencia de democratización de la comunicación tampoco parece del todo real. Algo así le ocurrió a George H. Gallup, fundador del Instituto Americano de Opinión Pública (1935), quien veía en las encuestas de comienzos del siglo XX una forma de hacer partícipe al pueblo de las decisiones políticas. Aún carecemos de investigaciones y datos suficientes para poder conocer con detalle la trascendencia que Internet y las tecnologías móviles están teniendo en la conformación de la opinión pública. Sin embargo, su uso generalizado es una realidad palpable, y el comportamiento público ya no responde a las mismas pautas de finales del siglo pasado. Queda por evaluar, mediante análisis de casos que respondan a contextos diferentes, si el dirigismo mediático y político que ha condicionado a la opinión pública de los últimos tiempos está dando lugar a un nuevo fenómeno social de

21. QUESADA, Montserrat (2009): "Construir la sociedad del conocimiento. Dos retos urgentes", en: GARCÍA GALINDO, J. A., VASALLO DE LOPES, $M^{a}$ I., y VERA BALANZA, $M^{a}$ T. (Coords.), Construir la sociedad de la comunicación. Madrid, Tecnos, pág. 349.

22. KATZ, James E. (2008): Op. Cit., pág. 26. 
construcción de la opinión pública desde la sociedad misma. O si, por el contrario, estamos ante un nuevo espejismo.

\section{Epílogo: la memoria digitalizada y la opinión pública}

La conformación de la opinión pública tiene que ver con la relación que el ciudadano mantiene con el relato del presente, pero una cuestión que la diferencia de la de las épocas anteriores es la posibilidad de que el ciudadano interactúe fácilmente con los relatos del pasado, gracias al acceso electrónico a los documentos audiovisuales, sonoros, o impresos, digitalizados. Esta posibilidad abre un extraordinario camino a la preservación del patrimonio de la humanidad, aspecto éste en el que ha insistido Rosa Franquet, quien apela a la dimensión social de la comunicación frente a su rentabilidad comercial ${ }^{23}$. La radio y la televisión a la carta, o las plataformas en las que se comparten vídeos y fotografías, con independencia de sus distintos modelos de negocio, son ofertas propiciadas por la digitalización de estos medios, que permiten a los usuarios la audición y el visionado de programas ya emitidos, que están a disposición del público en los archivos audiovisuales colgados en la Web. Esta forma de ver la televisión u otros documentos audiovisuales modifica radicalmente los usos anteriores, pues el ciudadano ya no está sujeto al horario de emisión de la programación, salvo que previamente hubiera sido grabada por el usuario, lo que condicionaba el tiempo de ocio de los televidentes y estructuraba la vida familiar en torno a ella. Esta oferta a la carta es parte de nuestra memoria audiovisual.

El descubrimiento y la relectura del pasado a través de ese importante patrimonio cultural constituido por el fondo documental digital en red (impreso, audiovisual o sonoro), sitúa al usuario ante la posibilidad de revisitar ad líbitum dicho patrimonio como parte de su propia memoria histórica. Esta facilidad y esta forma de acceder a los contenidos del pasado, ya sean informativos o de entretenimiento, permiten su recreación individual y colectiva, dando lugar a procesos cognitivos de empatía que favorecen el aprendi-

23. FRANQUET, Rosa (2009): "Elementos del pasado para interpretar los retos de la convergencia digital", en: GARCÍA GALINDO, J. A., VASALLO DE LOPES, Mª I., y VERA BALANZA, $M^{a}$ T. (Coords.), Construir la sociedad de la comunicación. Madrid, Tecnos, pág. 363. Refiriéndose a los documentos audiovisuales, esta autora se expresa en los siguientes términos: "La idea de que obras audiovisuales, generadas con el dinero público, se consideren un patrimonio de la humanidad debería rescatarse del olvido para garantizar el acceso a la memoria histórica. En la fase actual de desarrollo social, en un contexto de globalización, constreñir el conocimiento que se puede obtener a través de los documentos audiovisuales a su rentabilidad comercial, considerándolos como simples productos mercantiles, tiene poco sentido. La dimensión social de la comunicación debería ponerse en las agendas de los políticos para contrarrestar la concepción actual dominante basada exclusivamente en la idea del producto audiovisual como una mercancía más". 
zaje y la asimilación de dichos contenidos. Cuando esta posibilidad no existía, el conocimiento del pasado era meramente referencial e ilustrativo, y se percibía como algo muy lejano y sin relación con el presente. En el nuevo escenario tecnológico, el pasado está más cerca de nosotros. Aunque el conocimiento histórico nunca puede ser suplido por cualquier recreación, sino que ha de ser resultado del estudio de las fuentes originales y de las obras científicas, el acceso a las fuentes de nuestra propia memoria histórica facilita, sin embargo, la comprensión del pasado y nos proporciona nuevos códigos para entender el presente. La opinión pública se nutre también de estas representaciones, que en la Sociedad de la Información son transmitidas a través de numerosas plataformas de comunicación. Este legado patrimonial se suma al cada vez mayor volumen de información que se despliega a través de las redes sociales, blogs, bitácoras y otras plataformas existentes en Internet. La posibilidad de que los usuarios de estos sitios electrónicos archiven sus vídeos, sus fotografías, sus comentarios, etc., multiplican considerablemente el valor patrimonial de toda esa documentación.

Como hemos escrito en las páginas precedentes, las nuevas tecnologías de la información y de la comunicación no solo han facilitado la interactividad, sino que además ha convertido a los ciudadanos en productores de contenidos que pueden ser difundidos públicamente. Estas capacidades están modificando, sin duda, las reglas de comportamiento de la opinión pública tradicional. Tan solo la adaptación a los nuevos medios supone alterar los hábitos comunicativos de la población, y cuando el uso de estos se generaliza se modifica la dinámica interna de la opinión pública. La percepción del pasado y del presente se ven modificadas por la mayor sofisticación de esas tecnologías de mediación, que acercan más y mejor al ciudadano a las fuentes de información, y le permiten diseñar con criterio personal su propio itinerario formativo e informativo. Si el objetivo de los medios de comunicación y de los políticos en la sociedad industrial fue lograr el consentimiento de la opinión pública en torno a los grandes problemas sociales; en la actualidad, la ruptura del monopolio informativo de los medios de comunicación tradicionales, y el desarrollo de nuevas industrias de la cultura asociadas las nuevas tecnologías, dificultan aquel consenso. Probablemente, asistamos en los próximos años a una pugna entre los supuestos fabricantes del consentimiento que se resisten a perder el control, y unos ciudadanos que exploran nuevas vías de expresión, de opinión y de comunicación en libertad. Quizás el pensamiento crítico, cuya ausencia en el periodismo denunciaba Walter Lippmann en la primera mitad del siglo XX, pueda tener una oportunidad en la sociedad postindustrial, sobre todo si el periodismo acierta a refundarse sobre sus bases más irrenunciables, y contribuye a construir junto a los ciudadanos una opinión pública con plena conciencia de los problemas del mundo. 


\section{Referencias bibliográficas}

La Sociedad de la Información en España. 2010. Ariel, Colección Fundación Telefónica. Consultado en: http://e-libros.fundacion.telefonica.com/sie10/.

AGUADO, Juan Miguel, y JOSÉ MARTÍNEZ, Inmaculada (Coords.) (2008): Sociedad móvil. Tecnología, identidad y cultura. Madrid, Biblioteca Nueva.

CARLSSON, Ulla (2011): "Los jóvenes en la cultura de los medios digitales", en Infoamérica, 5.

COLA, Marta, PRARIO, Benedetta, y RICHERI, Giuseppe (2010): Media, tecnologie e vita cuotidiana: la domestication. Roma, Carocci editore.

DADER, José Luis (2009): "Periodismo en la hipermodernidad: consecuencias cívicas de una identidad débil (y algunas vías de reconstrucción)", en: Textual \& Visual Media, 2.

FRANQUET, Rosa (2009): "Elementos del pasado para interpretar los retos de la convergencia digital", en: GARCÍA GALINDO, J.A., VASALLO DE LOPES, $M^{\text {a }}$ I., y VERA BALANZA, M ${ }^{\mathrm{a}} \mathrm{T}$. (Coords.), Construir la sociedad de la comunicación. Madrid, Tecnos.

FUENTES, Juan F. y FERNÁNDEZ SEBASTIÁN, Javier (2008): "El lenguaje de la democracia: ¿crisis conceptual o crisis del sistema?", en: Revista de Occidente, 322.

GARCÍA GALINDO, J.A., VASALLO DE LOPES, Mª I., y VERA BALANZA, $M^{\mathrm{a}} \mathrm{T}$. (Coords.), Construir la sociedad de la comunicación. Madrid, Tecnos.

GÓMEZ-MOMPART, Josep Lluis (2009): "Construir la sociedad de la comunicación desde la historia", en GARCÍA GALINDO, J.A., VASALLO DE LOPES, $M^{a}$ I., y VERA BALANZA, $M^{\mathrm{a}} \mathrm{T}$. (Coords.), Construir la sociedad de la comunicación. Madrid, Tecnos.

KATZ, James E. (2008): "Cuestiones teóricas en torno a medios móviles y comunicación", en: AGUADO, Juan Miguel, y JOSÉ MARTíNEZ, Inmaculada (Coords.) (2008): Sociedad móvil. Tecnología, identidad y cultura. Madrid, Biblioteca Nueva.

MONZÓN, Cándido (2001): "Opinión e imagen pública. Una sociedad bajo control", en: Palabra Clave, 9.

QUESADA, Montserrat (2009): "Construir la sociedad del conocimiento. Dos retos urgentes", en: GARCÍA GALINDO, J.A., VASALLO DE LOPES, Ma I., y VERA BALANZA, M ${ }^{\mathrm{a}} \mathrm{T}$. (Coords.), Construir la sociedad de la comunicación. Madrid, Tecnos.

SAHAGÚN, Felipe (2009): "El futuro del periodismo", en: Cuadernos de Periodistas, 17. 